\title{
El territorio como víctima. Ontología política y las leyes de víctimas para comunidades indígenas y negras en Colombia
}

\author{
Territory as Victim. Political Ontology and the Laws for Victims \\ of Indigenous and Afrodescendant Communities in Colombia
}

\author{
Daniel Ruiz Serna* \\ McGill University (Canadá)
}

\begin{abstract}
RESUMEN
La Ley de Víctimas para pueblos indígenas incluye el reconocimiento del territorio como una víctima más del conflicto armado en Colombia. Haciendo uso de la ontología política como herramienta de análisis, argumento que tal inclusión va más allá de la protección y restitución de derechos de uso y goce de la propiedad colectiva. En su lugar, este reconocimiento puede interpretarse como una oportunidad para pensar una serie de efectos que el conflicto armado ha provocado en conjuntos disímiles de agencias no-humanas que hacen parte sustancial de los territorios de pueblos indígenas y de comunidades negras. El texto explora algunas consecuencias políticas, epistemológicas y ontológicas que pueden derivarse de dicha medida.
\end{abstract}

Palabras clave: territorio, ontología, víctimas, indígenas, comunidades negras.

\begin{abstract}
The Victims and Land Restitution Law for indigenous peoples includes the recognition of their territories as victims of the armed conflict in Colombia. Through the use of political ontology as an analytical framework, it is argued that such recognition is not limited to the protection and restitution of rights regarding collective property. Instead, the idea of territory as a victim encompasses a set of damages that extend beyond humans as the armed conflict has also affected the myriad of non-human beings that are an essential part of indigenous and Afro-Colombian territories. This paper explores some political, epistemological, and ontological consequences of such measure.
\end{abstract}

Keywords: territory, ontology, victims, indigenous people, Afro-Colombian communities.

\footnotetext{
* Candidato doctoral en Antropología de McGill University. Sus últimas publicaciones incluyen: "Los debates del giro ontológico en torno al naturalismo moderno" (2016), en Revista de Estudios Sociales 55: 193-204. y "Threads of Life and Death: A Photo Essay on Hunting and Fishing in Northwest Amazonia" (2015), en Visual Anthropology Review 31 (1): 73-86. daniel.ruiz-serna@ mail.mcgill.ca.
} 


\section{Introducción ${ }^{1}$}

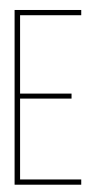

n el Bajo Atrato (Chocó) algunas personas aseguran que la constante presencia de hombres armados ha espantado a las fieras y a los espíritus o encantos que solían habitar las selvas y ríos que constituyen los territorios colectivos de comunidades negras. Líderes de las comunidades indígenas embera katío del Alto Andágueda (Chocó) denunciaron el riesgo al que se ha expuesto su soberanía alimentaria por cuenta de los bombardeos que enfurecieron a los jaï o espíritus primordiales que protegen ciertos animales, quienes decidieron dejar algunas presas de caza fuera del alcance de la gente (J. L. Quiroga, comunicación personal, Bogotá, agosto del 2015). Por otra parte, un indígena wiwa de la Sierra Nevada de Santa Marta expresa que la presencia de actores armados ha "maltratado y asesinado" sus territorios sagrados: "Por esta violencia nuestros padres espirituales que viven en el agua, los árboles, las plantas y las piedras ya se sienten muy poco” (CMH 2015). Estos ejemplos permiten entrever que para algunas comunidades indígenas y negras del país las experiencias de la guerra no se agotan en el daño ocasionado a la gente, sino que sus consecuencias se inscriben también en la miríada de seres que habitan sus territorios. La desaparición de encantos, de espíritus protectores de animales o de padres espirituales describe una serie de efectos que trascienden los ámbitos humanos y que afectan no tanto los derechos de las personas como el entramado de relaciones en el que gente, lugares y agencias no-humanas participan ${ }^{2}$.

En el 2011, y en el marco de una serie de políticas para el reconocimiento de los derechos de las víctimas del conflicto armado en Colombia, las organizaciones indígenas y de comunidades negras, cada una por separado, concertaron

1 Quiero agradecer a Natalia Quiceno, Nicolás Espinosa, Camilo Gómez y Carlos Del Cairo por la lectura que hicieron de versiones preliminares de este escrito. El texto también se benefició de los agudos comentarios de tres evaluadores anónimos y de los editores de esta revista, quienes me plantearon desafíos de gran envergadura metodológica y conceptual. Es mi responsabilidad si esta versión no hace justicia a sus brillantes sugerencias.

Agencia, en su sentido más amplio, es la capacidad que tiene un agente para actuar en un mundo dado. Esa capacidad de actuación varía según la escuela de pensamiento que se adopte. Siguiendo a Descola (2006), Kohn (2013), Latour (2008, 2013) y Viveiros de Castro (2010), en este texto entiendo agencia como la capacidad que tienen muchas entidades nohumanas (espíritus, animales, plantas, lugares) de crear relaciones, de generar y participar en asociaciones o redes de significado a través de atributos que les son propios: intencionalidad, subjetividad, representación, sentido o lenguaje. En un lugar como el Bajo Atrato, por ejemplo, los espíritus, muchos animales, plantas y minerales, así como ciertos lugares y aun algunos objetos, poseen intencionalidad y con ello la capacidad de influir a voluntad en múltiples acontecimientos de la vida social. 
con el Estado una serie de leyes mediante las cuales se dictaron medidas de asistencia, reparación y restitución de derechos territoriales a las víctimas pertenecientes a estos grupos étnicos. En concreto, el Decreto-Ley 4633 del 2011, también conocido como Ley de Víctimas para Comunidades Indígenas, incorporó la noción del territorio como víctima:

El territorio, comprendido como integridad viviente y sustento de la identidad y armonía, de acuerdo con la cosmovisión propia de los pueblos indígenas y en virtud del lazo especial y colectivo que sostienen con el mismo, sufre un daño cuando es violado o profanado por el conflicto armado interno y sus factores vinculados y subyacentes. (Art. 45)

Atendiendo, entre otros, a "la especial relación [...] espiritual que tienen los pueblos indígenas con su territorio" (art. 8) o al "vínculo especial y colectivo que los une con la madre tierra” (art. 3), la ley reconoce la importancia del territorio en tanto garante primordial de la pervivencia física y cultural de estos pueblos. En tal sentido, el decreto fija medidas para la reparación y restitución del territorio como un derecho fundamental de estas comunidades. Al examinar los efectos del conflicto armado en los términos descritos en el Bajo Atrato, el Alto Andágueda o la Sierra Nevada de Santa Marta, puede interpretarse que la inclusión del territorio como víctima abonaría el camino para el reconocimiento, al menos en teoría, del territorio como un eventual sujeto de derechos. No en vano el decreto describe el territorio como sustrato material e "integridad viviente" (art. 45).

La inclusión del territorio en la Ley de Víctimas comparte algunas similitudes con los giros biocéntricos (Gudynas 2009) de las constituciones de Bolivia y Ecuador $^{3}$, o con las luchas de pueblos indígenas en países como Brasil, Paraguay, Perú o Canadá, donde las demandas por derechos sobre tierras y recursos naturales adoptan un lenguaje que privilegia el parentesco, los vínculos espirituales o los atributos subjetivos de ciertos elementos del paisaje en vez de la propiedad (Blaser 2013a; De la Cadena 2015). Como señala De la Cadena (2010), estas demandas desafían el tipo de política a la que estamos acostumbrados, pues movilizan relaciones, prácticas y entidades que ponen en entredicho la separación radical

La Constitución de Ecuador dedica todo el capítulo séptimo a los derechos de la Naturaleza o Pacha Mama. Por su parte, la Constitución de Bolivia reconoce "la pluralidad vigente de todas las cosas ["montañas, ríos, lagos"] y nuestra diversidad como seres y culturas" (Constitución Política de Bolivia, preámbulo ఇ1). He de aclarar que los efectos sociojurídicos de estos reconocimientos constitucionales son sustancialmente distintos al caso colombiano, puesto que el Decreto-Ley 4633 es apenas un texto normativo mediante el cual el Congreso de la República le otorga facultades al Poder Ejecutivo para la atención y reparación a las víctimas pertenecientes a los pueblos indígenas. Aunque con fuerza material de ley, el decreto-ley tiene un rango inferior a una constitución política, norma jurídica suprema de los Estados de derecho. 
que los Estados modernos han establecido entre los reinos de la naturaleza - y la ciencia como su legítimo interlocutor-y los reinos de lo humano - con la política como su principal aliado (341-342). En su lugar, el lenguaje adoptado pareciera trasladar a la esfera pública una serie de actores - encantos, jaï, espíritus protectores-que desestabilizan las ya porosas fronteras entre lo vivo y lo inerte, entre sujetos y objetos, o entre aquello que Latour (2004) describe como hechos (lo dado, lo natural, lo real) y valores (lo construido, lo social, lo creído).

En este artículo de reflexión examino algunas de las consecuencias políticas, epistemológicas y ontológicas que podrían derivarse de la inclusión del territorio como víctima del conflicto armado. Argumento que, además de movilizar una serie de derechos para la protección de la propiedad colectiva y de los marcos culturales con los que ciertas comunidades estructuran su relación con el mundo, dicha inclusión también podría hacer posible que los llamados territorios étnicos y los conjuntos heterogéneos de seres que participan activamente en la vida de muchas de estas comunidades se reconozcan como sujetos de derechos, es decir, como sujetos con valores intrínsecos que son independientes de los derechos ya asignados a los humanos ${ }^{4}$. Me muevo en un terreno hipotético, especulativo, si se quiere, en el que planteo un marco de posibilidades políticas que tendría la Ley de Víctimas, no sus efectos sociojurídicos 5 . Adopto una perspectiva que, siguiendo el trabajo de Mario Blaser (2009a, 2009b, 2012, 2013b), identifico como ontología política, y me pregunto si la inclusión del territorio como víctima puede decirnos algo, no solo de los efectos que el conflicto armado ha ocasionado en las visiones del mundo que comparten ciertos grupos humanos, sino sobre la naturaleza misma de los daños al territorio y de sus eventuales posibilidades de reparación.

La ontología política puede definirse como una herramienta "políticoconceptual" que, por un lado, da cuenta del tipo de política que otorga sentido y modela el conjunto de prácticas que sostienen un mundo o una ontología dada y, por el otro, del tipo de conflictos y de negociaciones que tienen lugar cuando

4 La noción de sujeto de derechos implica el reconocimiento de una entidad, individual o colectiva, como titular de derechos y deberes que son regulados por un marco legal particular. Como examina Gudynas (2009) en el caso ecuatoriano, el reconocimiento de los no-humanos en tanto sujetos de derechos implica tres componentes: ético (el debate sobre los valores que les son propios), moral (las obligaciones que se derivan para su protección) y político (sanciones y regulaciones legales) (38).

5 Lo más seguro es que, al seguir aquella corriente dominante de interpretación jurídica en la que se privilegia la textura abierta de los derechos garantizados en la Constitución (I. Jaramillo 2003, 15-17), la inclusión del territorio derive en un conjunto de derechos y obligaciones que serán definidos por un juez o mediante jurisprudencia de la Corte Constitucional, a partir de las circunstancias de algún caso específico. En otras palabras, el repertorio de efectos sociojurídicos y de obligaciones legales que dicho reconocimiento acarrea estaría aún por definirse. 
diversos mundos $\mathrm{u}$ ontologías se encuentran y se esfuerzan por mantener su propia existencia y marco de inteligibilidad (Blaser 2009a, 2009b). En este texto, ontología hace referencia al conjunto de premisas y prácticas a través de las cuales se define qué mundos y qué clase de seres existen o pueden existir (Descola 2006), las condiciones que posibilitan dichas existencias (Kohn 2015) y el conjunto de obligaciones o relaciones que estas generan (Latour 2013). Según Escobar (2014, 2015), la ontología política puede entenderse también como el análisis de los procesos por medio de los cuales se producen distintas realidades o mundos, así como las luchas que se dan para que dichos mundos no sean atrapados en la "trampa epistémica" de la "realidad única" o "un solo mundo", propios de la modernidad secular $(2015,34)$. En especial, Escobar identifica como práctica política ontológica la dimensión política de la ontología ("toda ontología o visión del mundo crea una forma particular de ver y hacer política”) y la dimensión ontológica de la política (toda política pone en marcha premisas particulares sobre lo que existe y puede existir) $(2014,98)$. Por ejemplo, en un lugar como el Bajo Atrato, los efectos del conflicto armado suponen disputas de orden ontológico cuando ciertas comunidades indígenas describen las consecuencias de la presencia paramilitar en sus territorios, en términos del alejamiento de los espíritus protectores de los animales de caza, o cuando algunas comunidades negras manifiestan las dificultades de retornar a sus caseríos porque se encuentran habitados por los espíritus de aquellos que sufrieron una mala muerte . $^{6}$

Al adoptar una perspectiva de ontología política, veo en la inclusión del territorio como víctima una oportunidad que tienen las organizaciones de comunidades indígenas y negras para hacer visible una variedad de daños ocasionados

Una de las críticas al llamado giro ontológico es su radicalización y, por momentos, esencialización de la alteridad, pues esta aparece muchas veces como un fenómeno ininteligible e inconmensurable (véanse, por ejemplo, Bessire 2014; Bessire y Bond 2014; Ramos 2012). Aunque la sombrilla del giro ontológico puede cubrir una diversa gama de autores y propuestas metodológicas y conceptuales (véase el balance presentado por Kohn 2015), un común denominador es el interés por dar cuenta de las realidades co-constitutivas o mundos en los que humanos y no-humanos participan activamente. Inspirado fundamentalmente en los trabajos de Descola, Viveiros de Castro y Latour, el giro ontológico problematiza la existencia de una sola realidad o un único universo al que se tiene acceso a través de ciertas construcciones sociales. En su lugar proponen un pluriverso, una suerte de entramado en el que distintos mundos comparten conexiones parciales, se entrelazan, se encuentran e interactúan entre sí (Blaser 2009a; De la Cadena 2015). Una consecuencia de este enfoque es que la alteridad, esto es, la multiplicidad de modos de existencia y de maneras de relacionarse con el mundo no es simplemente la consecuencia de la diversidad humana, sino que es el resultado de la existencia de "diferentes mundos per se" (Holbraad 2010, 183). Al alinearme con una perspectiva ontológica no sostengo que las experiencias de daño al territorio de comunidades indígenas y afro sean inherentemente inconmensurables, sino que muchas de estas experiencias no están siendo consideradas en el marco de aplicación de la Ley de Víctimas. Considerar dichas experiencias tendría consecuencias en las medidas de justicia, verdad y reparación que puedan implementarse. 
a un conjunto disímil de seres donde lo humano es apenas una instancia más, y no siempre la más importante. Dicha inclusión es también una oportunidad que tiene el Estado colombiano para diseñar políticas de atención y reparación que sean consecuentes con tal diversidad de existencias. Ahora bien, mi análisis de los decretos de víctimas se centra en la textualidad misma de las normas - lo que ellas describen- más que en el conjunto de prácticas legales que permitieron la inclusión del territorio como víctima en la legislación. Deliberadamente, omito los procesos sociojurídicos, los discursos de representación o las estrategias de negociación e interpretación que dieron lugar a dicha textualidad, pues lo que me interesa acentuar es el carácter ontológico de tal inclusión, es decir, la interpretación de algunos daños provocados por el conflicto armado. Buena parte de mis argumentos se desprende de mi experiencia etnográfica en el Pacífico colombiano, de donde derivo algunos ejemplos puntuales de lo que caracterizo como daños al territorio y que me permiten ilustrar mi argumento, a saber: las consecuencias del conflicto armado se extienden más allá de los derechos de los humanos, puesto que la guerra también ha afectado a un conjunto heterogéneo de agentes no-humanos que son parte fundamental de las experiencias que comunidades indígenas, negras e incluso campesinas mantienen con los lugares que habitan.

El texto está dividido en tres partes. En la primera, examino algunas de las diferencias entre los decretos para comunidades negras e indígenas y argumento que dicha normatividad reproduce ciertas prácticas legales en torno a las identidades étnicas y a sus posibilidades espaciales de reivindicación. Siguiendo el trabajo de Diana Bocarejo (2011, 2015), tomo prestado el concepto de tipología - formas de pensar y situar espacialmente las identidades étnicas - para plantear que, en el marco de las políticas de verdad, justicia y reparación, "ideas sedimentadas" sobre lo que significa "ser indígena y vivir e imaginar un lugar" $(2015,27)$ posibilitan, pero también silencian, demandas relacionadas con los daños al territorio y sus posibilidades de reparación. En la segunda parte señalo cómo ciertos efectos territoriales de la guerra exceden el lenguaje ambiental y ponen sobre el tapete un conflicto de carácter ontológico. Este conflicto resulta no tanto de la inconmensurabilidad de las experiencias de ciertas comunidades, sino de la dificultad de pensar dichas experiencias en un marco que trascienda las presunciones epistemológicas que reifican las fronteras entre creencias (o construcciones culturales de la realidad) y la realidad misma ${ }^{7}$. En la tercera

7 Aunque en esa sección amplío un poco los ejemplos que cito, en este artículo me concentro en la reflexión que suscitan estos casos más que en su descripción etnográfica. Dicha descripción se encuentra en mi tesis doctoral (Ruiz, en preparación). 
parte describo lo que considero el carácter emancipador de la inclusión del territorio en calidad de víctima: es una invitación a descentrar lo humano como locus de la restitución de derechos y una oportunidad para continuar desestabilizando las fronteras entre el reino de los hechos (lo dado, lo natural, lo real) y el reino de los valores (lo construido, lo social, lo creído).

\section{Múltiples maneras de entender el territorio}

La Ley 1448 del 2011 o Ley de Víctimas del Conflicto Armado Interno fue criticada por muchas organizaciones indígenas y afros del país, puesto que el Gobierno nacional no las tuvo en cuenta en la formulación de un conjunto de políticas que les concernían directamente. Ante el evidente riesgo de inexequibilidad que corría la ley ${ }^{8}$, el Congreso le otorgó facultades al presidente de la República para que realizara procesos de consulta previa y expidiera los decretos para regular los derechos de las víctimas de estas minorías étnicas. Para ello, el Gobierno acudió a dos instancias organizativas que, en teoría, representan y defienden los intereses de los pueblos indígenas y comunidades negras: la Mesa Permanente de Concertación ${ }^{9}$ y la Consultiva de Alto Nivel $^{10}$. Cada instancia redactó por separado, y con sus respectivos equipos técnicos, los documentos legales en los que consignaron sus aspiraciones sobre asistencia, atención, reparación y restitución de derechos. De este proceso resultaron los decretos-leyes 4633 y 4635 del 2011: el primero para "pueblos y comunidades indígenas” y el segundo para "comunidades afrocolombianas, negras, raizales y palenqueras".

Ambos decretos comparten un mismo espíritu: reconocen el grado de vulnerabilidad de estos pueblos en el marco del conflicto armado, los consideran sujetos de especial protección y señalan que, por sus características históricas y culturales, han sufrido daños de carácter colectivo que requieren medidas especiales de atención. Pero hay diferencias sustanciales en los contenidos de

8 La inexequibilidad es un acto por el que la Corte Constitucional declara sin efecto una norma que está contra la Constitución o los principios allí establecidos.

9 La Mesa Permanente de Concertación con los Pueblos y Organizaciones Indígenas fue creada por el Decreto 1397 de 1996 y tiene como misión evaluar y concertar con el Estado la ejecución de políticas administrativas y legislativas susceptibles de afectar a estos pueblos.

10 La Consultiva de Alto Nivel de Comunidades Negras, Afrocolombianas, Raizales y Palenqueras fue creada mediante el artículo 45 de la Ley 70 de 1993 y tiene la función de hacer seguimiento a las disposiciones legales contempladas en esta ley. 
ambos decretos que son el resultado del tipo de instancias organizativas que participaron en su redacción, de la manera en que se desarrollaron los respectivos procesos de consulta previa y, más importante, de la forma en que histórica y jurídicamente a indígenas y afros se les han reconocido distintas identidades étnicas, lo que los vincula de manera diferencial en el armazón legal del Estado colombiano. Una de las principales diferencias en los decretos tiene que ver con el modo como asumen el llamado enfoque diferencial. Por ejemplo, en el caso indígena, el decreto desarrolla sus propias definiciones de conceptos claves, como víctimas o daños, propone particulares medidas de protección y reparación a las mujeres, y plantea disposiciones especiales en temas de vivienda y de ayuda humanitaria. En cambio, el de comunidades negras se apega con frecuencia a los contenidos de la criticada Ley 1448 en temas como la reparación o la atención diferencial por género, y presenta definiciones ambiguas o muy vagas de conceptos como víctima o daño, lo que pone en entredicho el enfoque étnico que debía adoptar ${ }^{11}$.

En términos de derechos territoriales, ambos decretos reconocen los regímenes especiales de propiedad y la importancia que tiene el territorio como soporte fundamental de la existencia física, la pervivencia cultural y el desarrollo autónomo de estas comunidades. Sin embargo, cada uno lo hace de manera cualitativamente distinta. En el caso indígena, el decreto menciona en su objeto y ámbito la "protección, reparación integral y restitución de derechos territoriales", mientras que el de comunidades negras menciona "asistencia, reparación integral y restitución de tierras” (énfasis añadido). Las diferencias entre protección y asistencia o entre derechos territoriales y restitución de tierras no son semánticas sino de enfoque. En el caso del territorio, el Decreto 4633 hace referencia a "vínculos especiales y colectivos" con "la madre tierra" (art. 3), a la "convivencia armónica en los territorios” (art. 29), a la "entidad viviente” (art. 45) o al "carácter sagrado y de ancestralidad” de estos (art. 33). En cambio, el Decreto 4635 tan solo reconoce el derecho fundamental de las comunidades negras al territorio, "en virtud de la estrecha relación cultural que mantienen con los mismos" (art. 40), y únicamente establece los daños al territorio en términos ambientales (“afectación de los ecosistemas", art. 9) o de propiedad ("abandono, confinamiento y despojo”, art. 110).

El modo en que los decretos de víctimas abordan el territorio y sus posibles daños acentúa la manera diferencial en que el Estado ha reconocido histórica y jurídicamente una serie de derechos y de relaciones territoriales entre las comunidades étnicas -indígenas y negras-, y entre estas y otras sociedades rurales análisis de la Consultoría para los Derechos Humanos y el Desplazamiento (Codhes 2013). 
o campesinas. En el caso étnico, la diferencia entre ambos decretos no significa que los indígenas hayan ganado más derechos que los afrocolombianos a la hora de exigir respeto por sus territorios colectivos ${ }^{12}$. El punto, más bien, es que los decretos profundizan cierto derrotero por el que las identidades indígenas y negras pueden transitar. En términos históricos o jurídicos esto no es una novedad, puesto que las identidades étnicas de dichos grupos han tenido trayectorias muy disímiles en el seno de las estructuras institucionales que reconocen sus derechos. No obstante, los términos invocados en la Ley de Víctimas — que no son neutrales pues con ellos se disputa la realidad y se construye el mundo-confieren a los indígenas ciertos atributos y formas de territorialidad que de una u otra manera son omitidos en el caso de las comunidades negras, y que tampoco son reconocidos por el Estado a colectividades que sustentan sus demandas por el reconocimiento de derechos en una adscripción étnica (i. e. sociedades campesinas).

Si bien el decreto que atañe a las comunidades negras no considera el territorio como víctima, ello no significa que muchas de estas comunidades no experimenten los impactos del conflicto en términos de daños a entidades nohumanas. De hecho, mi experiencia etnográfica en el Bajo Atrato da cuenta de cómo la guerra ha transformado las relaciones que ciertas comunidades negras mantienen con sus montes, sus ríos y los espíritus que los habitan. Investigaciones similares en otros contextos etnográficos podrían dar luz sobre cómo este tipo de experiencias de daño no se limita a ciertos grupos étnicos. De hecho, el énfasis en lo ontológico llama la atención sobre que determinados significados y experiencias emergen no tanto de las creencias que sean comunes a un grupo o de sus afiliaciones identitarias (Blaser 2012), sino del conjunto de prácticas, sensibilidades e interacciones que estos puedan desplegar en un momento o lugar particulares. En últimas y aunque la ley solo lo señale en el caso indígena, la posibilidad de describir ciertas experiencias del conflicto armado en términos de daños a las "especiales relaciones espirituales" o "vínculos colectivos" que distintas comunidades cultivan con sus territorios no se limita a las condiciones sociales, culturales e históricas que el Estado admite únicamente en el caso indígena ${ }^{13}$.

Por ejemplo, las comunidades negras pueden invocar tratados internacionales sobre derechos humanos tales como el Convenio 169 de la OIT, o la legislación nacional que reconoce el vínculo indisociable entre comunidades étnicas y los territorios que históricamente han habitado (la Ley 70, las sentencias C-169 y T-955, o el Auto 005 del 2009 de la Corte Constitucional son algunos ejemplos).

13 Dado que existe una serie de daños provocados por el conflicto armado que no son vistos o leídos apropiadamente por el Estado, su reconocimiento es una de las formas de propiciar condiciones para su reparación, de manera que se favorezcan los objetivos de verdad, justicia 
Aunque el reconocimiento de los territorios indígenas como víctimas del conflicto armado se produce en un contexto específico de negociación política entre la Mesa Permanente de Concertación con los Pueblos Indígenas y el Estado colombiano, encuentro en él un germen capaz de alterar la manera en que el Estado ha regulado - y construido fronteras en el proceso- las relaciones entre lo que se considera dado o natural y lo que se considera cosmología o representación cultural de la realidad. Me explico: al multiculturalismo como política cultural, es decir, "las formas de pensar y gobernar la diferencia étnica" (Bocarejo 2015, 32), y al marco epistemológico en que se produce dicha política les es inherente una particular operación intelectual: la separación entre lo universal o lo público (los intereses, prácticas y valores que el Estado promueve en nombre de una sociedad mayoritaria), y lo particular o privado (los intereses, prácticas y valores adscritos a las llamadas cosmovisiones de ciertos pueblos). Al incluir al territorio como una víctima, la legislación estaría promoviendo, entonces, cierto reconocimiento sobre las fronteras cada vez más porosas entre los reinos de lo dado o natural (kosmos) y de lo construido o lo cultural (politikos). Siguiendo la propuesta cosmopolítica de Stengers (2005b) sobre la posibilidad de integrar estos dos reinos, veo en dicho reconocimiento una posibilidad para matizar algunas formas de razonamiento y una oportunidad para poner en evidencia el lugar desde donde el Estado regula las relaciones entre lo público y lo privado, entre lo universal y lo particular, entre la ciencia y la creencia.

El cuestionamiento de estas relaciones entre kosmos y politikos ha estado presente desde hace un tiempo en el seno del Estado, especialmente en la manera en que la Corte Constitucional ha legislado ciertos asuntos indígenas. Por ejemplo, en una sentencia del 2011 la Corte advertía que, en los procesos de consulta previa, los significados privilegiados de conceptos como desarrollo, progreso y cultura "son los del Estado y de la sociedad mayoritaria, porque los criterios de definición y de medición surgen de la legislación del Estado y del concepto de un bien común exclusivo y excluyente a otras epistemologías" (Sentencia T-129 del 2011, 59. Énfasis añadido). En estos postulados se percibe que en mucha de la jurisprudencia colombiana está presente aquello que Stengers (2005a) define como arreglo diplomático, es decir, un arreglo en el que las partes que representan maneras radicalmente distintas de entender el mundo reconocen la ausencia de un modelo epistemológico y ontológico soberano. Sin embargo, hasta ahora, tal arreglo ha adoptado la forma de un debate epistemológico - las condiciones que posibilitan el conocimiento del mundo-, cuando podría llevarnos también

y reparación para las víctimas que no pertenecen o no se identifican como comunidades indígenas. 
a una pregunta sobre la naturaleza del mundo y de los seres que lo habitan, es decir, a un debate ontológico. Esta posibilidad está presente cuando se piensan algunos de los efectos del conflicto armado en términos de daños al territorio, como lo examino a continuación.

\section{Daños al territorio}

En la legislación de víctimas para comunidades indígenas y negras, el concepto de territorio tiene múltiples acepciones: algunas veces aparece como un lugar que posibilita la emergencia de ciertos rasgos culturales; otras, como una entidad viviente, y otras, simplemente como propiedad. En esta sección quiero llamar la atención sobre cierto tipo de daños que pueden invocarse al pensar el territorio como una víctima. Para ello entiendo el territorio no tanto como un sustrato material o un espacio discreto, delimitado, externo e independiente de la gente, sino como un tipo de experiencia anclada en lugares específicos y generadora de sentidos y significados (Kenny 1999; Oslender 2008; Tilley 1994). Entendido como una forma de experiencia profundamente localizada (Escobar 2001), el territorio puede compararse con aquello que Williams (1977) llama estructura de sentimientos, es decir, una instancia estructurada por y estructurante de un conjunto de percepciones, experiencias vividas y valores que son comunes a aquellos que comparten un lugar. En tanto estructura, este conjunto de experiencias modela las aproximaciones de la gente a los lugares que habita (Basso 1996) y es modelado, a su vez, por las cualidades de conjuntos disímiles de agencias humanas y no humanas (Latour 2004). El territorio, además de ser una construcción social en la que se despliegan prácticas culturales, económicas y simbólicas (Lefebvre [1974] 2000), puede pensarse también como un evento (Casey 1996), una instancia relacional más que material (Latour 2008) que posibilita la producción de sentidos que son encarnados (embodied) por quienes lo habitan, y que se manifiestan en sus cuerpos, hábitos y sensibilidades (Escobar 2008; Hirsch 1995; Nazarea 2006).

Una de las virtudes de la ley es que, al invocar al territorio como víctima, esta no se abstrae de la multiplicidad de experiencias que distintas comunidades mantienen con sus lugares: "La reparación integral de los derechos territoriales incluye el saneamiento espiritual conforme a las tradiciones culturales y ancestrales de cada pueblo, cuando al criterio de las autoridades tradicionales dicho saneamiento sea necesario" (art. 8, énfasis añadido). El "saneamiento espiritual” como medida de reparación solo puede ser valorado por las comunidades 
implicadas y teniendo en cuenta las particularidades de sus relaciones con el territorio, puesto que un hecho que algunos consideren daño puede no ser asumido como tal por otros. Para el Estado resulta difícil determinar ciertos tipos de daños al territorio, aunque hay una serie de afectaciones más o menos ponderables: aquellas descritas como daños ambientales.

Desde el reemplazo de grandes extensiones de bosques naturales por miles de hectáreas de palma de aceite en los territorios colectivos de comunidades negras y mestizas en el río Curvaradó (Chocó), hasta la construcción de un parque eólico en territorio wayúu en La Guajira (P. Jaramillo 2014), pasando por la extracción de oro en el resguardo embera katío del Alto Andágueda (Chocó), este tipo de intervenciones pone en evidencia los conflictos existentes en torno al goce pleno de los derechos a la propiedad. En este sentido, las afectaciones de tipo ambiental que se dan por la explotación abusiva e ilegal de los territorios de estas comunidades - daños que se enmarcan en la destrucción material de sus propiedades colectivas en tanto bienes protegidos constitucionalmentepueden ser reparadas dentro de un marco que, al menos en teoría, no desafía drásticamente las rutas tradicionales de reparación jurídica: o se repara a las comunidades con medidas tendientes al restablecimiento de la integridad de los ecosistemas afectados (rehabilitación o saneamiento ambiental) o se restituye el patrimonio con algo equivalente o con una enmienda correspondiente al valor del bien dañado (Lozano 2010). En el marco del conflicto armado, muchas de las demandas sobre afectaciones territoriales tienen que ver con transformaciones severas del paisaje, con los daños a los que ha sido expuesto el territorio en su calidad de garante de la pervivencia cultural de estas comunidades. En otras palabras, los daños ambientales exponen una serie de disputas frente a los derechos de uso y goce de la propiedad pero no implican, estrictamente hablando, el reconocimiento de que el territorio pueda ser un agente, una entidad viva o una víctima por sí mismo.

En esta línea de razonamiento adquiere sentido el apartado del Decreto 4633 que estipula que, si bien el territorio es una víctima, "los titulares de derechos [...] son los pueblos y comunidades indígenas y sus integrantes individualmente considerados” (art. 3). Por supuesto, el territorio no tiene voz propia para denunciar los daños de los que es objeto, y si la tuviera seguramente sucedería lo mismo que con el león wittgenstiano: nadie lo entendería. Por ello, solo las comunidades afectadas por los daños infligidos al territorio pueden hablar por él y son ellas las que, dentro del marco jurídico, se convierten en sujetos de restitución y reparación de derechos. Pero si atendemos a lo que dicen los médicos tradicionales o líderes espirituales de la Sierra Nevada de Santa Marta o de 
Chocó, en muchas ocasiones el territorio sí tiene voz y su inteligibilidad recae en personas que, como ellos, actúan como interlocutores privilegiados. El punto es que la inclusión del territorio como víctima abre un abanico de posibilidades para enumerar una serie de daños que no se agotan en las afectaciones ambientales ni en las reparaciones de dichas afectaciones. Me explico: lo referente a la restitución de derechos sobre el disfrute de la propiedad trata más de los derechos de estas comunidades sobre sus territorios pero, desde la perspectiva ontológica que propongo, la inclusión del territorio como víctima habla más bien —o también-de derechos del territorio. Este matiz hace toda la diferencia y tiene el potencial de abrir un escenario de acción política para que las comunidades puedan disputar los términos con los que el Estado interpreta ciertos daños que, en las perspectivas de reparación, suelen ser asignados a la esfera "material" (lo que suele describirse como daños ambientales), a la esfera "moral" (lo que se define como perjuicios psicológicos) o a la esfera "cultural” (que la Corte Interamericana de Derechos Humanos o la Corte Constitucional describen como amenazas a las diferencias de ser y actuar en el mundo que encarnan estos pueblos). Algunos casos tomados de mi trabajo de campo en el Bajo Atrato ilustran este punto ${ }^{14}$.

En el 2003, en Riosucio hubo una racha de suicidios de niños emberas que algunos jaibanás atribuyeron a un monstruoso espíritu que consumía sus almas. Este y otros seres malignos suelen habitar las partes más recónditas de la selva, pero los muertos provocados por los enfrentamientos entre guerrilla y paramilitares que no fueron enterrados sino abandonados en el monte dejaron a este ser fuera de control, a tal punto que los ritos y cantos tradicionales de los jaibanás resultaron insuficientes para apaciguarlos. Algo similar manifiestan algunas personas de las comunidades embera y tule del municipio de Unguía, quienes en el 2015 describieron a los abogados de la Unidad de Restitución de Tierras algunos de los problemas que habían tenido para obtener cosechas aceptables o acceder a las presas de caza, los cuales, según ellos, se originaron a raíz de las fosas comunes cavadas por ejércitos paramilitares cerca de sus resguardos (J. L. Quiroga, comunicación personal, Bogotá, agosto del 2015). Según algunos jaibanás, los jaïs que habitan ciertos lugares y que son los dueños o espíritus protectores de los seres que viven en la selva, incluyendo animales y plantas,

14 El daño y la reparación son componentes importantes de mi argumentación pero, más que una propuesta sobre el tipo de reparaciones que deberían asociarse al reconocimiento del territorio como víctima, centro mi atención en cómo podría ser movilizada la ley para describir una serie de daños que rebasan lo humano. En el contexto de las comunidades indígenas y afros, los planes de reparación colectiva previstos en la ley son el escenario perfecto para estudiar la caracterización del daño y las propuestas de reparación que estas comunidades están formulando. 
se han enfurecido y alejado por este hecho. Para los jaibanás, las negociaciones que suelen emprender con estos jaïs para que dejen algunos de sus animales al alcance de la gente se han tornado difíciles, lo que en definitiva ha causado que se deba pasar muchos más trabajos para obtener carne de monte. En ambos casos el daño es ubicado en agencias no-humanas y es desencadenado por eventos inéditos - combatientes sin enterrar, fosas comunes-que desafían sus marcos ontológicos tradicionales. Al ubicar el daño en los espíritus que habitan la selva, ambas comunidades están llamando la atención sobre el hecho de que la guerra ha transformado no solo la vida de la gente sino también la de diferentes clases de seres y las condiciones de los lugares que habitan. Esta serie de transformaciones severas en las relaciones que la gente mantiene con un entramado de agencias no-humanas es uno de los elementos susceptibles de invocación cuando se considera al territorio como víctima.

En el río Curvaradó, también en el Bajo Atrato, algunos miembros de las comunidades mestizas y negras, que retornaron a sus territorios ocho años después de haber sido desplazados por los grupos paramilitares de las Autodefensas Campesinas de Córdoba y Urabá (ACCU), encontraron sus tierras ocupadas por grandes extensiones de palma de aceite sembradas por empresarios que formaron alianzas criminales con grupos paramilitares (Franco y Restrepo 2011; Vargas 2016). Miembros de estas comunidades cuentan que ahora se encuentran muchas más serpientes que antaño y que sus mordeduras se "traman” con facilidad, es decir, se agravan y se vuelven mortales, a tal punto que no pueden ser tratadas con su medicina tradicional, que es, en muchos casos, la única forma de tratamiento ante la ausencia de servicios básicos de salud en la región. La palma, sostienen algunos, envenenó la tierra y la gente ha tenido que redoblar esfuerzos para lidiar con las fuerzas hostiles que ahora pululan en estos territorios. En el resguardo indígena Eyákera del municipio de Unguía, las comunidades emberas que lograron ratificar sus derechos sobre sus tierras ancestrales (Sentencia 010 del 2016) solicitaron, como medida de preservación de la integridad de su territorio, la siembra de ciertos árboles cuyos dueños espirituales pueden contribuir a negociar con los espíritus que protegen a los animales del monte. Dicha reforestación podría ayudarles a recobrar su soberanía alimentaria, puesto que tras la siembra de cultivos de coca, de la cual los grupos guerrilleros y paramilitares derivaban su sustento, mucha selva desapareció y, con ella, los animales de caza. En ambos casos, los daños asociados con transformaciones violentas de los paisajes se inscriben en una lógica que no describe sus efectos en términos ambientales solamente. No se trata de que la gente en Curvaradó no establezca relaciones de causalidad entre la presencia de palma y la abundancia de serpientes, 
tal y como ha sido documentado en Guatemala (Escalón 2014) o en otras regiones de Colombia (Lynch 2015) ${ }^{15}$, ni de que las comunidades del resguardo Eyákera ignoren que, al permitir la regeneración del bosque, ciertas plantas atraerían insectos y aves polinizadoras, que a su vez darían lugar al crecimiento de especies de cuyos frutos se alimentan grandes roedores y otras presas de caza. En estos casos, lo que sucede no es simplemente que la gente esté usando el lenguaje de lo cultural para dar cuenta de las mismas conclusiones a las que un biólogo o un agrónomo podrían llegar. Se trata, más bien, de que en Curvaradó o en Unguía las comunidades están señalando fenómenos muy distintos, con ciertas manifestaciones ecológicas - sobrepoblación de víboras venenosas, ausencia de animales de caza - pero que apuntan a relaciones de la gente con los territorios y los seres que los habitan, que no se agotan en el lenguaje de la rehabilitación ambiental.

Debido a que en casos como los anteriores las comunidades afectadas apuntan a fenómenos distintos, las reparaciones eventuales no deberían limitarse a resolver exclusivamente el tema ambiental, pues de nada serviría, por ejemplo, reforestar si los jaibanás no pueden realizar los actos indispensables de negociación con los dueños de los animales. Por ello es que, además de la restauración de unas condiciones ecológicas perturbadas, como lo propone el juez de la República que falló a favor de las comunidades del resguardo Eyákera ${ }^{16}$, las acciones de reparación al territorio también tendrían que orientarse al restablecimiento de relaciones entre la gente, sus territorios y los demás seres presentes. En Eyákera lo que se debería atender no es simplemente el restablecimiento de relaciones simbióticas entre especies animales y vegetales sino de relaciones de intercambio y reciprocidad entre dueños espirituales. Lo que está en juego en Curvaradó no es solo el control de las víboras mediante la erradicación de las palmas, sino las maneras de tratar adecuadamente los efectos de un veneno sembrado por los palmicultores y que se introduce en los cuerpos de la gente a través de las serpientes.

De hecho, las serpientes parecen estar tomándose los cultivos de palma de aceite como nuevos hábitats. Lynch (2015) ha reportado hasta 38 especies diferentes, de las cuales cerca del 33\% son venenosas. Según el investigador, los desechos que se arrojan tras la recolección de los frutos favorecen las condiciones para la reproducción de ranas y ratones, alimento favorito de las serpientes (173).

En razón de las afectaciones territoriales documentadas por la Unidad de Restitución de Tierras, un juez ordenó, entre algunas medidas de reparación, la elaboración y concertación de "un plan de restauración y manejo sostenible del ecosistema forestal", el fomento de "estrategias de seguridad alimentaria e iniciativas productivas" y la "implementación de proyectos productivos agropecuarios", aunque hizo la salvedad de que estos últimos deben atender a las "costumbres y tradiciones ancestrales" de las comunidades afectadas (Sentencia 010 del 2016). 
Estos casos ponen de manifiesto aquello que Viveiros de Castro (2004) llama equivocaciones controladas: malentendidos que ocurren cuando dos interlocutores (en este caso las comunidades indígenas y negras, por un lado, y el Estado y las instituciones encargadas de la restitución de derechos a las víctimas, por el otro) no están hablando del mismo asunto (la naturaleza del daño y las posibilidades de reparación) pero no lo saben. Esta diferencia de términos también manifiesta un conflicto de tipo ontológico, es decir, disputas que ocurren no porque diferentes interlocutores tengan distintas representaciones del mundo, sino porque ellos "no son conscientes de que distintos mundos están siendo promulgados (y asumidos) por cada uno de ellos” (Blaser 2009b, 11) ${ }^{17}$. Lo que me interesa resaltar es que los esfuerzos que haga el Estado para reparar ciertos daños al territorio no deberían restringirse al restablecimiento de los derechos de la gente, ni a proteger sus cosmologías o sus representaciones culturales de la realidad, sino que deberían ayudar a reparar los vínculos con las entidades no humanas que hacen parte constitutiva de sus respectivos territorios o mundos. Por supuesto que, al no entender el lenguaje en el que se manifiestan los padres espirituales o espíritus protectores, el Estado no puede realizar tales reparaciones, pero sí las facilitaría identificándolas y legitimándolas como un elemento fundamental y no solo contingente de los planes de reparación colectiva para comunidades negras e indígenas.

Los ejemplos mencionados me llevan a considerar dos cosas: primero, que el conflicto armado y sus efectos en comunidades indígenas y negras no pueden ser entendidos plenamente si no se tienen en cuenta sus experiencias y relaciones con los lugares que habitan. Segundo, que estas formas de violencia producen transformaciones tanto individuales como colectivas, muchas de las cuales comprenden no solo a los humanos y sus respectivas “representaciones” del mundo, sino también a los mundos de los espíritus, de los animales y de los objetos con los que interactúan estas comunidades. Si bien en los llamados daños ambientales el Estado y las comunidades afectadas pueden encontrar un terreno común para promover la protección de los derechos territoriales y hacer respetar el uso y goce de la propiedad colectiva, los ejemplos expuestos permiten entrever que ciertos efectos del conflicto no se agotan en lo ambiental, entendido en función de los derechos de las comunidades. En tal sentido, el reconocimiento del territorio como víctima hablaría más de derechos del territorio que de derechos sobre el territorio. Usando la ontología política como marco interpretativo, sostengo que la posibilidad de ver al territorio como un agente que puede convertirse en

17 Texto original: "Those unaware that different worlds are being enacted (and assumed) by each of them". 
potencial víctima es una invitación a atender "la diferencia”, no solo en términos de los marcos culturales con los que distintos grupos interpretan el mundo, sino en términos del mundo mismo que puede ser conocido (De la Cadena 2015; Holbraad 2010; Stengers 2005b).

\section{Ontología política}

En el 2012, en una de las ediciones preparadas para la Colección Cuadernos Legislación y Pueblos Indígenas de Colombia, Paula Gaviria (entonces directora de la Unidad para la Atención y Reparación a Víctimas) y Gabriel Muyuy (director del Programa para el Desarrollo Integral de los Pueblos Indígenas) hicieron una presentación del Decreto-Ley 4633 en la que señalaron que, durante su formulación, funcionarios y autoridades indígenas mantuvieron un "diálogo de saberes” en el que la inclusión del territorio como víctima "da[ba] cuenta del reconocimiento sociopolítico a la diversidad de epistemologías y relaciones entre el hombre y la madre tierra que prima con sus diferentes variantes en el pensamiento indígena” (Presidencia de la República 2012, 8-9).

La expresión madre tierra es importante puesto que aparece en el capítulo dedicado al objeto y ámbito de la ley, específicamente en la definición de víctima: "Para los pueblos indígenas el territorio es víctima, teniendo en cuenta su cosmovisión y el vínculo especial y colectivo que los une con la madre tierra” (art. 3). Madre tierra es una expresión polivalente a la que se fuerza a portar una serie de sentidos que varían de acuerdo con quien la usa. Considerando algunos de los efectos que ha generado el conflicto, madre tierra daría cuenta de una serie de entidades - humanas, no humanas, sobrehumanas-, del conjunto de vínculos que comparten y de sus manifestaciones en ciertos lugares. En el contexto de la ley, madre tierra sirve para describir los lazos "espirituales”, "simbólicos” o "culturales" que estos pueblos cultivan con aquello que, en términos modernos, llamamos naturaleza. La concepción de la naturaleza como madre ha calado perfectamente en el discurso público por cuenta de esa asociación que empezó a gestarse en la década de los sesenta entre ambientalismo y movimientos indígenas, una asociación que reinventaba a los indígenas como personas más próximas a la naturaleza y poseedores de una sabiduría ancestral para manejar el medio ambiente (Nadasdy 2005; Ulloa 2004). Para los no-indígenas, madre tierra ha llegado a posicionarse como una metáfora capaz de describir un acervo de relaciones con la naturaleza que ahora se consideran posibles (Povinelli 1995). En el caso 
de la Ley de Víctimas, madre tierra es una equivocación controlada; el Estado y las organizaciones indígenas pueden no estar hablando del mismo asunto sin saberlo. Madre tierra posiblemente aluda a las conexiones que algunas comunidades sostienen con una intrincada red de seres dotados de agencia y voluntad, de las experiencias con los lugares que habitan o de las relaciones "respetuosas", "sostenibles" o "espirituales" que mantienen con algo que otros tienden a llamar naturaleza. En el contexto de esta ley, el término es una traducción, una suerte de equivalencia que permite cierta comprensión mutua entre distintas realidades. Esto no quiere decir que, mediante su uso, los pueblos indígenas que participaron en el diseño de la normatividad no sean capaces de transmitir algunos de los sentidos que hallan en sus territorios y que los llevan a considerarlos víctimas. Más bien, madre tierra opera como un término (expresión) que les permite a los pueblos indígenas realizar una serie de exigencias de reconocimiento en condiciones que son inteligibles para el Estado colombiano.

Algo similar ocurre cuando en el Decreto 4633 se comparan ciertos daños al territorio con profanaciones (art. 44), o cuando en la defensa de los territorios de comunidades indígenas y afros se apela a convenciones internacionales que condenan los ataques a "lugares de culto que constituyen el patrimonio cultural o espiritual de los pueblos" (art. 16, Protocolo II adicional a los Convenios de Ginebra de 1949). El uso de cierto lenguaje religioso ${ }^{18}$ para describir las expresiones de cuidado, reciprocidad o respeto que sustentan ciertas relaciones de estas comunidades con los lugares que habitan busca volver inteligibles un conjunto de experiencias que el Estado moderno solo reconoce dentro de una esfera religiosa. Este lenguaje facilita la comprensión de algunas de las experiencias que las comunidades viven con sus territorios pero no agota los sentidos que sustentan sus prácticas y relaciones, y aún menos las consecuencias que acarrea el conflicto armado. Al pensar en términos de profanaciones o de lugares sagrados, por ejemplo, se establece una serie de distinciones entre humanos, nohumanos, espíritus o dioses que pueden no existir entre muchas comunidades, o

18 El problema no es la definición semántica de daño sino las premisas de las que se parte para caracterizarlo. Por ejemplo, en las perspectivas de reparación propias de los contextos de justicia transicional, el daño, cuando se trata de personas, se sitúa o bien en una dimensión física o bien en una dimensión psicológica. Cuando se sitúa fuera de ellas, el daño se suele formular en términos ambientales. En ambos casos se reifican fronteras entre lo real y lo construido, entre lo que le pertenece a la gente y lo que le pertenece al "mundo", lo cual puede tener poco sentido entre muchas sociedades que, como las indígenas o las afrocolombianas, no manejan las dicotomías cuerpo/mente o naturaleza/cultura, propias de la ontología moderna. 
simplemente reifican fronteras inexistentes entre ámbitos sagrados y profanos ${ }^{19}$. Si bien la comparación entre las relaciones con el territorio y lo religioso es útil para referirse a experiencias que de otra manera resultarían ininteligibles dentro del marco epistemológico moderno, el lenguaje religioso no borra las diferencias existentes entre formas muy distintas de experimentar ciertos lugares (De la Cadena 2015).

La inclusión del territorio en una ley concebida para la atención, protección y reparación de víctimas posibilita un campo de interlocución y transacción con el Estado en el que diferentes comunidades logren describir las afectaciones que van más allá de los humanos. Pero, para hacerlo dentro del marco de derechos existente, se deberán usar términos (expresiones y condiciones) reconocibles socialmente. Esto nos lleva a examinar "el reconocimiento sociopolítico de epistemologías” del que hablan Gaviria y Muyuy. Tal reconocimiento, no importa qué tan bienintencionado sea, opera dentro de unos límites formales muy bien definidos en los que la modernidad y el multiculturalismo - entendido como la valoración positiva de la diversidad cultural- funcionan como matrices que trazan horizontes de posibilidad y fijan fronteras, algunas veces porosas (Latour 1993), entre lo real y la creencia, lo natural y lo cultural, lo público y lo privado. Me refiero a que el multiculturalismo es un tipo de arreglo político que reconoce la excepcionalidad de ciertos grupos humanos, pero lo hace actualizando las fronteras entre los pares que acabo de enumerar, es decir, valorando positivamente ciertas cosmovisiones o construcciones culturales de la realidad sin poner suficientemente en cuestión la existencia de una "realidad única" o "un solo mundo" (Escobar 2015, 34).

Al denominarse como una nación pluriétnica y multicultural, el Estado colombiano reconoce la existencia de diferentes formas de ver el mundo y promueve el tipo de "diálogo de saberes" y "reconocimiento sociopolítico de epistemologías” de los que hablan Gaviria y Muyuy. Pero el relativismo epistemológico que subyace a la promoción de la diversidad de cosmovisiones no cuestiona la hegemonía del Estado como determinante primario de lo real, es decir, como árbitro que regula las relaciones entre aquello que puede considerarse dado o natural y aquello que no sería sino representaciones culturales de esa realidad (Blaser 2013b; De la Cadena 2015; Escobar 2015). En otros términos, el reconocimiento

Esto no implica un tipo de inconmensurabilidad de las experiencias que indígenas y afros derivan de sus territorios. El punto es, más bien, que dichas experiencias se hacen legibles cuando se formulan en ciertos términos (expresiones y condiciones). Además, expresiones como madre tierra o profanaciones tienen particulares trayectorias históricas y sociales que, aunque útiles en determinados contextos, no agotan los significados que ciertas comunidades encuentran en sus territorios. 
sociopolítico de epistemologías valora unas construcciones culturales específicas de la realidad (desde dónde se paran unos y otros para entender el mundo), pero no pone en cuestión la naturaleza de esa realidad (qué tipo de mundo existe y cuáles son las entidades que lo constituyen). Por supuesto que tal cuestionamiento no puede ser objeto de una ley de víctimas, pero aun así la posibilidad de extender el marco de derechos al territorio y a un conjunto disímil de no-humanos es una invitación a pensar que la diferencia de experiencias que se derivan de ciertos eventos, como el conflicto armado, es resultado no simplemente de la diversidad de culturas que interpretan el mundo, sino de la multiplicidad misma de mundos o de realidades promulgadas (enacted) que conviven y se relacionan entre sí (Holbraad 2010).

A mi modo de ver, la inclusión del territorio como víctima representa un triunfo político para las organizaciones indígenas, pero cuando dicho reconocimiento se piensa exclusivamente en términos de cosmovisiones, es decir, de diferentes visiones de un mismo cosmos o mundo, se está adoptando un tono en el que el Estado ha de acogerse al respeto de las creencias agenciadas por ciertos actores a los que considera como legítimos otros ${ }^{20}$. El asunto es que cuando algunos experimentan cierto tipo de daños causados por la guerra en términos de encantos que han desaparecido o de dueños de animales que esconden a las presas de caza, no se está representando lo que está sucediendo, sino que se le está presentando tal y como es vivido (Holbraad 2008). La idea de que aquello corresponde a una particular cosmovisión surge en el proceso epistemológico mediante el que se traducen esas vivencias, en el trabajo de convertir estos hechos en algo inteligible para quienes no habitamos esos mundos de encantos y espíritus protectores.

Al invocar a padres espirituales o a encantos que desaparecieron, los wiwas de la Sierra Nevada o las comunidades negras del Bajo Atrato están apelando a nociones sobre la constitución y el funcionamiento del universo (Handelman 2008, 181) y a principios sobre las características y relaciones de las entidades que lo habitan (Kapferer [1988] 2012, 79). Es decir, nos remiten a cuestiones ontológicas - la constitución del mundo y la lógica de relaciones entre los seres que lo conforman-y no meramente a cuestiones epistemológicas. Asumir términos ontológicos en vez de epistemológicos es una invitación a pensar no tanto la manera en que ciertas comunidades étnicas representan el mundo sino

20 Aunque el concepto cosmovisión es constantemente evocado y defendido tanto por comunidades y organizaciones indígenas como por jueces y magistrados, aquí subrayo que dicha noción funciona como un término (expresión y condición) que busca hacer inteligible una serie de experiencias y valores que contrastan con aquellas encarnadas por la sociedad mayoritaria. 
la naturaleza misma del mundo que puede ser conocido. En el caso del conflicto armado y del territorio como víctima, ese giro puede ayudarnos a pensar los efectos del conflicto desde una perspectiva en la que lo humano no sea fundamento último de derechos ni sujeto exclusivo de reparación.

Debido a que la diferencia entre conocimiento y creencia se sigue actualizando a través de políticas multiculturales que valoran la diversidad epistemológica representada por ciertos otros legítimos, el tipo de daños a padres espirituales, a dueños de animales o a protectores de piedras se sigue confinando a la esfera de sus propias cosmovisiones o creencias culturales, puesto que reconocer esos daños por fuera de esos términos (expresiones y condiciones) significaría que el Estado aceptaría la existencia material y no solamente cultural de esas entidades, lo cual pondría en entredicho los regímenes de verdad del actual marco jurídico liberal. Pero es precisamente aquí donde yace el potencial emancipador que encuentro en el reconocimiento del territorio como víctima, pues al describir en esos términos ciertos efectos del conflicto armado se podrían cimentar las bases para un debate sobre lo real y su legítima representación. Esta es, pues, la perspectiva que ofrece la ontología política.

Como mencioné, la ontología política hace referencia al tipo de conflictos y negociaciones que ocurren cuando diversas ontologías se esfuerzan por mantener su existencia en un campo político (Blaser 2009a, 2009b; Escobar 2014, 2015). El acento analítico de esta herramienta "político-conceptual" está en que no considera la existencia de una sola realidad o naturaleza a la que tienen acceso diferentes grupos a partir de sus representaciones culturales particulares. Más bien, adopta la premisa multinaturalista trabajada por Viveiros de Castro (1998): la suposición de que, más que una multiplicidad de representaciones acerca de un mismo mundo, lo que cambia cuando alguien aprehende la realidad desde su particular punto de vista es el mundo que puede ser conocido. El multinaturalismo, argumenta Viveiros de Castro (2010), invierte una de las fórmulas características de la cosmología multiculturalista moderna — "la unicidad de la naturaleza y la multiplicidad de las culturas” (34)_, y en su lugar interpreta la naturaleza bajo la forma de lo particular, situando las diferencias que existen entre distintas sociedades en el tipo de mundo que puede ser conocido más que en las representaciones que estas crean de la realidad ${ }^{21}$. Así, la ontología política asume que los conflictos que involucran perspectivas disímiles no tienen que ver con qué visión de la naturaleza está más cercana a la realidad —conflicto epistemológico- sino con el carácter mismo de lo que existe y puede ser

21 Una síntesis de los argumentos de Viveiros de Castro y de las implicaciones epistemológicas del multinaturalismo puede encontrarse en Ruiz Serna y Del Cairo (2016). 
conocido - conflicto ontológico-. En el caso del territorio como víctima, la ontología política serviría para dar cuenta de aquellas disputas por la definición misma del daño y de sus posibles reparaciones, más aún cuando el objetivo de las leyes de víctimas es promover políticas de verdad y justicia que sean consecuentes con las experiencias de las comunidades afectadas.

Desde una perspectiva de la política cultural, la inclusión del territorio como víctima puede ser entendida en los términos descritos por Gaviria y Muyuy: el reconocimiento que hace un Estado multicultural de una variedad de modos de ver el mundo. En esta lógica, uno se sentiría tentado a reconocer los importantes avances de la legislación nacional y a interpretar dicha inclusión como un logro de las organizaciones indígenas en el reconocimiento de sus derechos. Incluso, en el marco de las políticas culturales no habría más que apreciar la forma en que estas organizaciones lograron desafiar ciertas dinámicas de poder y polemizar los sentidos que el Estado quiso imprimirles inicialmente a las leyes de víctimas. Desde una perspectiva de ecología política, la inclusión del territorio daría cuenta de las disputas por el control, uso y protección de los derechos de propiedad sobre tierras colectivas y recursos territoriales, así como de los conflictos que emergen cuando la naturaleza es concebida y asumida de maneras radicalmente distintas. Aun si uno adopta cierto enfoque de la economía política, este reconocimiento serviría para problematizar el tipo de relaciones sociales que posibilitan la producción de significados sobre el territorio y sus usos. La ontología política, por su parte, nos invita a considerar el reconocimiento del territorio como víctima como un marco en el que los derechos humanos o las afectaciones a la gente no siempre son suficientes para referirse a los efectos que el conflicto armado ha generado, no solo entre comunidades indígenas sino también entre otras colectividades que también cultivan relaciones íntimas con los lugares que habitan.

\section{Conclusiones}

El Decreto-Ley 4633 marca un derrotero mayor en relación con las políticas de verdad, justicia y reparación para las comunidades indígenas del país. Mi lectura de la inclusión del territorio como víctima llama la atención sobre las posibilidades de reconocer una serie de efectos del conflicto armado que se extienden más allá de los humanos. Si esta inclusión ha de derivar en el reconocimiento de nuevos derechos (incluyendo los de agencias no-humanas), o la manera en que dicha inclusión está siendo tramitada o puede serlo dentro del armazón 
multiculturalista colombiano, son cuestiones de filosofía del derecho y de antropología jurídica que están por resolverse. De ahí la necesidad de pensar aquellas prácticas que Sally Merry (2006) define como vernacularización, es decir, los procesos de traducción y adaptación del derecho a formas que resulten consecuentes con el ethos y las necesidades de un contexto social determinado. Como llama la atención Bocarejo (2015) en su análisis sobre los conflictos por el ejercicio de derechos étnicos, es en esos procesos de vernacularización donde se puede hallar la manera en que las personas movilizan la ley e interpretan la vulneración de sus derechos (179). Prestar atención etnográfica a los actuales procesos de reparación colectiva podría dar luces sobre los alcances concretos que ha tenido la inclusión del territorio en la Ley de Víctimas y sobre las posibilidades emancipadoras que he enunciado aquí.

En cuanto al reconocimiento de derechos de minorías étnicas, Colombia tiene una legislación excepcional, y aunque los decretos para víctimas de comunidades indígenas y negras son en sí mismos portentosos, vistos en el contexto de las políticas multiculturales del país acentúan un discurso jurídico y unos imaginarios sociales en los que las identidades de estos grupos continúan siendo hiperespacializadas (Bocarejo 2011), es decir, condicionadas a una suerte de anclaje territorial que supone una asociación primigenia y una relación armónica entre estos grupos y los lugares que habitan. Según lo han analizado varios autores, dicha espacialización es particularmente evidente en el caso indígena y ha supuesto el traslape de los lenguajes de defensa de la diversidad cultural y la protección del medio ambiente (Bocarejo 2015; Chaves 2011; Del Cairo 2011; Ng’weno 2013; Restrepo 2002, 2013; Ulloa 2004; Wade 1996). En este sentido, resultaría pertinente preguntarse hasta dónde la inclusión del territorio en la Ley de Víctimas y, en especial, la preeminencia de lo ambiental en el momento de valorar los daños resultan instrumentales al ideario estatal de conservación y protección del medio ambiente.

Los términos planteados por la Ley de Víctimas y el análisis de ontología política que propongo no significan que el Estado haya aceptado de buenas a primeras la existencia de un rango de seres a los que hay que reconocerles derechos. Ya bastante hay con hacer respetar los derechos humanos consignados en un acervo importante de leyes y tratados internacionales. Lo que planteo son más bien posibilidades de reconocimiento de nuevos derechos y de formas de acción política que están implícitas en la noción del territorio como víctima. Veo en la ley un resquicio por el que se puede entrever un conjunto de operaciones que ponen en juego no solamente el reconocimiento de ciertos derechos culturales, sino un conjunto de definiciones que rebasan categorías aparentemente estables, 
como humanos/no-humanos o animado/inanimado. Al incluir al territorio en esta ley, las organizaciones indígenas seguramente no tenían como objetivo poner en tela de juicio el conjunto de tecnologías de poder mediante las cuales el Estado produce regímenes de verdad, razón o realidad. Mi presunción es que el marco de la Ley de Víctimas fue un escenario en el que estas organizaciones pudieron articular demandas en términos que fueron al mismo tiempo consecuentes con las realidades experimentadas a causa del conflicto y sintonizadas con el lenguaje propio de los derechos que han sido ya reconocidos por el Estado. En esos términos - expresiones y condiciones- es que los espíritus protectores, encantos o padres espirituales podrían entrar a la arena pública.

El ingreso (potencial) de estos seres por la vía de la victimización produce efectos que no pueden soslayarse. En primera instancia, la ley no está celebrando su existencia sino denunciando su vulnerabilidad: lo que se reconoce es aquello que el territorio está "dejando de ser" mas no "lo que es". Ello hace del reconocimiento del territorio como víctima un derecho esencialmente negativo en el sentido jurídico del término, es decir, se establece que estas comunidades no pueden ser privadas de aquello que, "en el ejercicio de su naturaleza humana, ha[n] adquirido legítimamente en el pasado y en derecho le[s] corresponda” (Auping $2004,1)$. En otras palabras, el territorio y su victimización se enuncian como el derecho negativo que tienen estas comunidades a no ser privadas de su propiedad o de sus tradiciones culturales y no como el reconocimiento de la diversidad de agencias que lo habitan. Otro asunto importante es que, al incluir al territorio como víctima, se delinea de entrada un tipo de política de asistencia que privilegia la restitución de ciertos derechos más que el reconocimiento de nuevos, lo cual no está exento de ciertos riesgos: por ejemplo, que las reparaciones al territorio asuman formatos altamente institucionalizados en los que el propio Estado fije sus condiciones de protección o que la victimización, tal y como la analiza P. Jaramillo (2014) para el caso de las identidades étnicas wayúus, pueda convertirse en catalizador de una agenda limitada de reivindicaciones territoriales.

Se ve, entonces, que a través del discurso de la victimización la ley reconoce en el territorio solo cierto tipo de agencia: una que puede limitar lo político a acciones de asistencia y de restitución. Pero, si nos atenemos a las posibilidades de relaciones y reconocimientos implícitos en la inclusión del territorio, lo político no se agota en el contrato social en el que se regulan las relaciones humanas sino que abarcaría otras agencias más allá de lo humano, cuyo lenguaje e inteligibilidad desafían los marcos epistémicos del Estado liberal moderno, por la simple razón de que, dentro de sus regímenes de verdad, este tipo de agencias solo pueden ser pensadas como realidades de ciertos sujetos étnicos. Así, pues, el 
reconocimiento del territorio como víctima lograría propiciar un tipo de política que no se agote en la restitución de unos derechos ya adquiridos sino que extienda el marco mismo de estos derechos, o al menos nos invitaría a contemplar uno en el que la existencia de padres espirituales, dueños de animales o encantos sean considerados seriamente.

Además de crear cierta sensibilidad política, la ontología política puede ser una herramienta de análisis que, en el contexto del conflicto armado colombiano y de las futuras políticas de verdad, justicia y reparación, ponga sobre la mesa varios cuestionamientos: ¿Qué tipo de daños son legibles en el actual marco de verdad, justicia y reparación? ¿Qué otras versiones acerca de los efectos generados por el conflicto se silencian o marginan y hasta qué punto el reconocimiento selectivo de esas otras versiones puede llegar a ser funcional para cierta perspectiva política de la justicia restaurativa? En resumen, ¿qué exigencias éticas estarían asociadas al cuestionamiento de lo político que supone la inclusión del territorio como víctima y al reconocimiento de un conjunto de agencias que rebasan lo humano? Mi propia convicción es que la desaparición de padres espirituales de las piedras y de los ríos, de encantos de la selva o de espíritus protectores de los animales dice tanto de los valores y sensibilidades cultivados por quienes con esos términos describen los daños del conflicto armado como del mundo mismo y de cómo este puede ser conocido.

\section{Referencias}

Auping, John. 2004. Introducción a El análisis económico de los derechos humanos, editado por Alejandro Guevara, Rodolfo de la Torre, Ignacio Llamas, Carlos Muñoz, Ricardo Solís y Ana María Tepichín, 1-5. Ciudad de México: Universidad Iberoamericana.

Basso, Keith. 1996. “Wisdom Sits in Places: Notes on a Western Apache Landscape”. En Senses of Place, editado por Steven Feld y Keith H. Basso, 53-90. Santa Fe: School of American Research Press.

Bessire, Lucas. 2014. Behold the Black Caiman. A Chronicle of Ayoreo Life. Chicago y Londres: The University of Chicago Press.

Bessire, Lucas y David Bond. 2014. “Ontological Anthropology and the Deferral of Critique”. American Ethnologist 41 (3): 440-456.

Blaser, Mario. 2009a. “Political Ontology”. Cultural Studies 23 (5): 873-896.

-. 2009b. "The Threat of the Yrmo: The Political Ontology of a Sustainable Hunting Program”. American Anthropologist 111 (1): 10-20. 
-. 2012. "Ontology and Indigeneity: On the Political Ontology of Heterogeneous Assemblages”. Cultural Geographies 21 (1): 49-58. DOI: 10.1177/1474474012462534.

-. 2013a. "Notes towards a Political Ontology of 'Environmental' Conflicts”. En Contested Ecologies: Nature and Knowledge, editado por Lesley Green, 13-27. Cape Town: HSRC Press.

-. 2013b. "Ontological Conflicts and the Stories of People in Spite of Europe”. Current Anthropology 54 (5): 547-568.

Bocarejo, Diana. 2011. "Dos paradojas del multiculturalismo colombiano: la espacialización de la diferencia indígena y su aislamiento político”. Revista Colombiana de Antropología 47 (2): 97-121. http://www.scielo.org.co/scielo.php?script=sci_abstract\&pid=S0486-65252011 000200005\&lng=es\&nrm=isoUniversitas.

- 2015. Tipologías y topologías indígenas en el multiculturalismo colombiano. Bogotá: Instituto Colombiano de Antropología e Historia, Pontificia Universidad Javeriana y Universidad del Rosario.

Casey, Edward. 1996. "How to Get from Space to Place in a Fairly Short Stretch of Time”. En Senses of Place, editado por Steven Feld y Keith H. Basso, 13-52. Santa Fe: School of American Research Press.

Centro de Memoria Histórica (CMH). 2015. "Indígenas se reúnen en la Sierra Nevada por sus víctimas y la memoria”. Consultado el 8 de abril del 2015. http://www.centrodememoriahistorica.gov.co/noticias/noticias-cmh/indigenas-se-reunen-en-la-sierra-nevada-porsus-victimas-y-la-memoria.

Chaves, Margarita. 2011. Presentación de La multiculturalidad estatalizada y configuraciones de estado, editado por Margarita Chaves, 9-24. Bogotá: Instituto Colombiano de Antropología e Historia.

Comité Internacional de la Cruz Roja. 1977. "Protocolo II adicional a los Convenios de Ginebra de 1949 relativo a la protección de las víctimas de los conflictos armados sin carácter internacional”. https://www.icrc.org/spa/resources/documents/misc/protocolo-ii.htm\#2.

Congreso de Colombia. 2011a. Decreto-Ley 4633. Por medio del cual se dictan medidas de asistencia, atención, reparación integral y de restitución de derechos territoriales a las víctimas pertenecientes a los pueblos y comunidades indígenas. Diario Oficial 48.278.

-. 2011b. Decreto-Ley 4365. Por medio del cual se dictan medidas de asistencia, atención, reparación integral y de restitución de tierras a las víctimas pertenecientes a comunidades negras, afrocolombianas, raizales y palenqueras. Diario Oficial 48.278.

Consultoría para los Derechos Humanos y el Desplazamiento (Codhes). 2013. "Reparación integral a pueblos y comunidades afrocolombianas. Decreto-Ley 4635 del 2011”. Documentos Codhes, vol. 27. Bogotá: Consultoría para los Derechos Humanos y el Desplazamiento (Codhes).

Corte Constitucional. 2011. Sentencia T-129 del 2011. http://www.corteconstitucional.gov.co/ relatoria/2011/t-129-11.htm.

De la Cadena, Marisol. 2010. "Indigenous Cosmopolitics in the Andes. Conceptual Reflections Beyond 'Politics'”. Cultural Anthropology 25 (2): 334-370.

- 2015. Earth Beings. Ecologies of Practice across Andean Worlds. Durham y Londres: Duke University Press. 
Del Cairo, Carlos. 2011. "Las jerarquías étnicas y la retórica del multiculturalismo estatal en San José del Guaviare”. Revista Colombiana de Antropología 47 (2): 123-149. http://www. redalyc.org/articulo.oa?id=105021311006.

Descola, Philippe. 2006. "Beyond Nature and Culture. Radcliffe's Brown Lecture in Social Anthropology 2005”. Proceedings of the British Academy 139: 37-155.

Escalón, Sebastián. 2014. “Palma africana: nuevos estándares y viejas trampas”. Plaza Pública. http://www.plazapublica.com.gt/content/palma-africana-nuevos-estandares-y-viejastrampas.

Escobar, Arturo. 2001. "Culture Sits in Places: Reflections on Globalism and Subaltern Strategies of Localization”. Political Geography 20: 139-174.

—. 2008. Territories of Difference. Place, Movements, Life, Redes. Durham y Londres: Duke University Press.

-. 2014. Sentipensar con la tierra. Nuevas lecturas sobre desarrollo, territorio y diferencia. Medellín: Ediciones Unaula.

—. 2015. “Territorios de diferencia: la ontología política de los ‘derechos al territorio’”. Cuadernos de Antropología Social 41: 25-38.

Franco, Vilma y Juan Restrepo. 2011. "Empresarios palmeros, poderes de facto y despojo de tierras en el Bajo Atrato”. En La economía de los paramilitares: redes de corrupción, negocios y política, editado por Mauricio Romero, 269-410. Bogotá: Corporación Nuevo Arco Iris.

Gudynas, Eduardo. 2009. "La ecología política del giro biocéntrico en la nueva Constitución de Ecuador”. Revista de Estudios Sociales 32: 34-47.

Handelman, Don. 2008. "Afterword: Returning to Cosmology-Thoughts on the Positioning of Belief”. Social Analysis 52 (1): 181-195.

Hirsch, Eric. 1995. "Landscape: Between Place and Space”. En The Anthropology of Landscape, editado por Eric Hirsh y Michael O’Hanlon, 1-30. Oxford: Clarendon Press.

Holbraad, Martin. 2008. "Definitive Evidence, from Cuban Gods". Journal of the Royal Anthropological Institute 14 (1): 93-109.

-. 2010. "Ontology is Just another Word for Culture: Against the Motion (2)". Critique of Anthropology 30 (2): 179-185.

Jaramillo, Pablo. 2014. Etnicidad y victimización. Bogotá: Ediciones Uniandes.

Jaramillo Sierra, Isabel. 2003. “Instrucciones para salir del discurso de los derechos.” En La crítica de los derechos, editado por Isabel Jaramillo Sierra, 11-42. Bogotá: Ediciones Uniandes, Instituto Pensar y Siglo del Hombre.

Kapferer, Bruce. (1988) 2012. Legends of People, Myths of State. Violence, Intolerance, and Political Culture in Sri Lanka and Australia. Washington: Smithsonian Institution Press.

Kenny, Michael. 1999. "A Place of Memory: The Interface between Individual and Collective History”. Comparative Studies in Society and History 41 (3): 420-437.

Kohn, Eduardo. 2013. How Forests Think: Towards an Anthropology beyond the Human. Berkeley: University of California Press. 
—. 2015. “Anthropology of Ontologies”. Annual Review of Anthropology 44: 311-327.

Latour, Bruno. 1993. We Have Never Been Modern. Cambridge MA: Harvard University Press.

- 2004. Politics of Nature: How to Bring the Sciences into Democracy. Cambridge MA: Harvard University Press.

-. 2008. Reensamblar lo social. Una introducción a la teoría del actor red. Buenos Aires: Manantial.

-. 2013. An Inquiry into Modes of Existence. An Anthropology of the Moderns. Cambridge (MA) y Londres: Harvard University Press.

Lefebvre, Henri. (1974) 2000. La production de l'espace. Chicago y París: Anthropos.

Lozano Acosta, Carlos. 2010. "El daño ambiental en los programas de reparación colectiva para comunidades indígenas y afrodescendientes afectadas por el conflicto armado en Colombia”. International Law: Revista Colombiana de Derecho Internacional 17 (1): 287-322.

Lynch, John. 2015. “The Role of Plantations of the African Palm (Elaeis guineensis Jacq.) in the Conservation of Snakes in Colombia”. Caldasia 37 (1): 169-182.

Merry, Sally Engle. 2006. Human Rights and Gender Violence: Translating International Law into Local Justice. Chicago: University of Chicago Press.

Nadasdy, Paul. 2005. "Transcending the Debate over the Ecologically Noble Indian: Indigenous Peoples and Environmentalism”. Ethnohistory 52 (2): 291-331.

Nazarea, Virginia. 2006. "Local Knowledge and Memory in Biodiversity Conservation”. Annual Review of Anthropology 35: 317-335.

Ng'weno, Bettina. 2013. “¿Puede la etnicidad reemplazar lo racial? Afrocolombianos, indigenidad y el estado multicultural en Colombia”. Revista Colombiana de Antropología 49 (1): 71-104. http://www.redalyc.org/pdf/1050/105029052004.pdf.

Oslender, Ulrich. 2008. Comunidades negras y espacio en el Pacífico colombiano. Hacia un giro geográfico en el estudio de los movimientos sociales. Bogotá: Instituto Colombiano de Antropología e Historia, Universidad Colegio Mayor de Cundinamarca y Universidad del Cauca.

Povinelli, Elizabeth. 1995. "Do Rocks Listen? The Cultural Politics of Apprehending Australian Aboriginal Labor”. American Anthropologist 97 (3): 505-518.

Presidencia de la República. 2012. Decreto Ley de Víctimas $N^{\circ} 4633$ de 2011. Colección Cuadernos Legislación y Pueblos Indígenas de Colombia n. ${ }^{\circ} 3$. Bogotá: Imprenta Nacional de Colombia.

Ramos, Alcida. 2012. “The Politics of Perspectivism”. Annual Review of Anthropology 41: 481-494.

República de Colombia. 2016. Sentencia restitutiva de derechos territoriales 010. Juzgado Primero Civil del Circuito Especializado en Restitución de Tierras de Quibdó, 5 de abril.

Restrepo, Eduardo. 2002. "Políticas de la alteridad: etnización de 'comunidad negra’ en el Pacífico sur colombiano”. Journal of Latin American Anhropology 7 (2): 34-59. 
—. 2013. Etnización de la negridad: la invención de las 'comunidades negras' como grupo étnico en Colombia. Popayán: Universidad del Cauca.

Ruiz Serna, Daniel. En preparación. "When Forest Run Amok. Political Violence and Territory in the Bajo Atrato Region”. Tesis de doctorado, Departamento de Antropología, McGill University.

Ruiz Serna, Daniel y Carlos Del Cairo. 2016. "Los debates del giro ontológico en torno al naturalismo moderno”. Revista de Estudios Sociales 55: 193-204.

Stengers, Isabelle. 2005a. “An Ecology of Practices”. Cultural Studies Review 11 (1): 183-196.

-. 2005b. "The Cosmopolitical Proposal”. En Making Things Public, editado por Bruno Latour y Peter Weibel, 994-1003. Cambridge MA: MIT Press.

Tilley, Christopher. 1994. A Phenomenology of Landscape. Oxford y Providence: Berg.

Ulloa, Astrid. 2004. La construcción del nativo ecológico. Bogotá: Instituto Colombiano de Antropología e Historia.

Unesco. 1954. Convención para la Protección de los Bienes Culturales en Caso de Conflicto Armado y Reglamento para la Aplicación de la Convención 1954. La Haya.

Vargas, Jennifer. 2016. “Despojo de tierras paramilitar en Riosucio, Chocó”. En El despojo paramilitar y sus variaciones: quiénes, cómo, por qué, editado por Francisco Gutiérrez y Jennifer Vargas, 121-146. Bogotá: Universidad del Rosario.

Viveiros de Castro, Eduardo. 1998. “Cosmological Deixis and Amerindian Perspectivism”. Journal of the Royal Anthropological Institute 4 (3): 469-488.

-. 2004. "Perspectival Anthropology and the Method of Controlled Equivocation". Tipití 2 (1): 3-22.

—. 2010. Metafísicas caníbales. Líneas de antropología postestructural. Buenos Aires: Katz.

Wade, Peter. 1996. "Identidad y etnicidad”. En Pacífico: ¿desarrollo o diversidad? Estado, capital y movimientos sociales en el Pacífico colombiano, editado por Arturo Escobar y Álvaro Pedrosa, 283-298. Bogotá: Cerec.

Williams, Raymond. 1977. Marxism and Literature. Oxford y Nueva York: Oxford University Press. 